\title{
Recycling Industrial Food Wastes for Lipids Production by Oleaginous Yeasts Rhodosporidiobolus Azoricus and Cutaneotrichosporon Oleaginosum.
}

\author{
Silvia Donzella \\ Università degli Studi di Milano: Universita degli Studi di Milano \\ Immacolata Serra \\ University of Milano-Bicocca: Universita degli Studi di Milano-Bicocca \\ Andrea Fumagalli \\ Università degli Studi di Milano: Universita degli Studi di Milano \\ Luisa Pellegrino \\ Università degli Studi di Milano: Universita degli Studi di Milano \\ Concetta Compagno ( $\square$ concetta.compagno@unimi.it) \\ La Statale: Universita degli Studi di Milano https://orcid.org/0000-0003-0760-2533
}

\section{Research}

Keywords: Microbial lipids, oleaginous yeasts, Rhodosporidiobolus azoricus, Cutaneotrichosporon oleaginosum, food wastes, yeast biomass

Posted Date: September 29th, 2021

DOI: https://doi.org/10.21203/rs.3.rs-934242/v1

License: (c) (i) This work is licensed under a Creative Commons Attribution 4.0 International License. Read Full License 


\section{Abstract}

Background

Microbial lipids have been emerging as a sustainable alternative to vegetable oils and animal fat to produce biodiesel and industrial relevant chemicals. The use of wastes for microbial processes can represent a way for upgrading low value feedstock to high value products, addressing one of the main goals of circular economy, the reduction of wastes by recycling. Two oleaginous yeasts, Rhodosporidiobolus azoricus and Cutaneotrichosporon oleaginosum, were used in this study to demonstrate the feasibility of the proposed approach.

Results

In this study wastes from industrial food processing, as pumpkin peels and syrup from candied fruits manufacture, were used for yeast cultivation and for lipids production. Evaluation of growth and sugar consumption revealed marked differences between the yeasts in capacity to utilize sucrose and glucose, the main sugars present in the feedstock. In particular, we observed an unexpected limitation in glucose metabolism on mineral media by $R$. azoricus. Both species showed ability to grow and accumulate lipids on media exclusively composed by undiluted pumpkin peels hydrolysate, and $R$. azoricus was the best performing. By a two-stage process carried out in bioreactor, this species reached a biomass concentration of $45 \mathrm{~g} / \mathrm{L}$ (dry weight) containing $55 \%$ of lipids, corresponding to a lipid concentration of $24 \mathrm{~g} / \mathrm{L}$, with a productivity of $0.26 \mathrm{~g} / \mathrm{L} / \mathrm{h}$ and yield of $0.29 \mathrm{~g}$ lipids per $\mathrm{g}$ of utilized sugar. These values are close to the highest reported so far from organic wastes.

Conclusions

Wastes from industrial food processing were sufficient to completely support yeast growth and to induce lipid accumulation. This study provides strong evidence that the concept of valorisation through the production of lipids from the complete metabolism of nutrients present in agro-industrial wastes by oleaginous yeasts is promising for implementation of biotechnological processes in a circular economy contest.

\section{Background}

Nowadays, the market is facing an increasing demand of triacylglycerols (TAGs) due to their application in a variety of industrial sectors. Depending on their composition, TAGs can be used not only for production of biodiesel, but also of other high value-added products such as, to cite some, biosurfactants, detergents, solvents, lubricants, adhesives, cosmetics and degradable polymers (Metzger and Bornscheuer, 2006; Foley et al. 2012; Koutinas et al. 2014; Liu et al. 2021; Zhang et al., 2021).

TAGs can be obtained by vegetable oils and animal fat, but their supply cannot be sustained only by these sources, due to the large land surfaces required for cultivation and the competition to food production (the so-called fuel $v s$ food conflict). For these reasons, more sustainable alternatives are continuously sought, and, in this context, microbial lipids (or single cell oils, SCOs) are considered as promising ones. They show in fact a very similar composition to vegetable oils but, in contrast, can be produced independently from geographic location, season changes, climate and by faster and controllable processes (Dyer et al., 2008; Beopoulos et al., 2011; Zhang et al., 2021). In addition to chemical applications, microbial lipids can be used also as components for animal feed (Béligon et al., 2016; Blomqvist et al., 2018).

SCOs are produced by oleaginous microorganisms that possess the unique ability to accumulate lipids, especially TAGs, over $20 \%$ and up to $70 \%$ of the dry cell mass. Known oleaginous yeasts belong to the genera Lipomyces, Yarrowia, Cryptococcus, Trichosporon as well as Rhodotorula and Rhodosporidium (Ageitos et al., 2011; Chattopadhyay et al. 2021). Several parameters have been reported to influence lipid production, such as pH, oxygenation, temperature, phosphate and sulphate limitation, but the most crucial one is the ratio between carbon and nitrogen (C/ $\mathrm{N}$ ratio) in the growth medium. Typically, when nitrogen level is low and the sugar content is still high (high $\mathrm{C} / \mathrm{N}$ ratio), the carbon flux is diverted from acetyl-CoA (via citric acid) towards fatty acid biosynthesis (Ageitos et al., 2011; Vorapreeda et al., 2012). Remarkably, given their increasing role played in the field of microbial oils production, some oleaginous species have been engineered in order to by-pass strict metabolic regulation mechanisms, to enlarge their substrate range, as well as to modify their FAs composition (Tai and Stephanopoulos, 2012; Qiao et al., 2017; Donzella et al., 2019; Chattopadhyay et al. 2021). Oleaginous yeasts show ability to grow using a variety of carbon sources, including those present in waste streams from the agro-food sector (Huang et al., 2013; Qin et al., 2017). For example, yeast-based production of oils has been reported using, among others, a wide range of lignocellulose wastes such as dried sorghum stalks (Matsakas et al., 2015), cardon stalks (Tasselli et al., 2018), wastes generated from oil palm industries (Ahmad et al., 2019), mixed vegetable waste (Chatterjee and Mohan, 2018), but also cheese whey (Carota et al., 2017). The generation of agro-food wastes is constantly rising due to rapid growth of world economics and population. In this regard, waste management is becoming a major concern, triggering the idea that wastes can be turned into a resource. Hence, economy has been increasingly shifted from linear to circular, with the aim to pursuit the ambitious goal of zero waste by conversion of wastes into energy and high value products. Suitable feedstock is characterized by low or null cost on the market, and this represents one of the main reasons that increase attractiveness of recycling. On the other hand, one of the principal costs that need to be addressed is related to the transport of the waste from the site where it is generated. Another important aspect related with costs is that utilization of wastes for microbial cultivation often involves physical and/or chemical pretreatments as well as enzyme processes, that are necessary for the release of sugars available for metabolism. Toxic compounds, including organic acids, aldehydes, and phenols can be generated during harsh pretreatments and can inhibit the growth, but detoxification methods are again costly. Conversely, wastes-based media often do not require supplementary ingredients, because they result already rich in macro- and micro-nutrients necessary to support microbial growth. This can reduce the costs of the process.

In this paper we explored the valorization of wastes derived from the food industry, in particular pumpkin peels and a syrup derived from candied fruits manufacture. Italy is among the main world producers of pumpkins, being placed ninth according to the FAO (Food and Agriculture Organization of the United 
Nations) statistics. By setting up a protocol of enzymatic hydrolysis we show the feasibility of producing yeast biomass rich in lipids using the oleaginous yeasts Rhodosporidiobolus azoricus (previously known as Rhodosporidium azoricum) and Cutaneotrichosporon oleaginosum (previously known

as Trichosporon oleaginosus) cultivated on media derived entirely from pumpkin peel wastes. In order to increase lipid accumulation, a syrup derived from candied fruits manufacture was utilized to unbalance the $\mathrm{C} / \mathrm{N}$ ratio in a two stage process carried out in bioreactor. This study provides strong evidence that the concept of valorization through the production of lipids from the complete metabolism of nutrients present in agro-industrial wastes by oleaginous yeasts is promising for implementation of biotechnological processes in a circular economy contest.

\section{Results And Discussion}

\section{Optimization of pumpkin peels pretreatments and quantification of components}

Although acid hydrolysis is often used for saccharification of lignocellulosic feedstock, its use generally requires specialized equipment and it is also accompanied by several drawbacks, such as the generation of several inhibitory compounds like furfural and acetic acid, that can hamper the growth of microorganisms (Jönsson and Martín, 2016). Enzymatic hydrolysis was then considered more effective as pretreatment. For this purpose, a commercial preparation containing a blend of cellulases, B-glucosidases, and hemicellulases, suitable for the degradation of cellulose and hemicellulose to fermentable sugars, was used. To optimize conditions of enzyme concentration and time of hydrolysis suited for the pumpkin peels treatment, assays were carried out. Different amounts of enzymes blend were added to the biomass (details reported in Methods), and the reactions were monitored by quantifying the released glucose (Table 1). We observed that a minimum of $24 \mathrm{~h}$ was required to obtain a liquefied mixture, indicating that the action of the enzymes was probably not complete before this time. The addition of $2.25 \mu \mathrm{L}$ of enzyme solution per $\mathrm{mL}$ of mixture allowed the release of $23.6 \mathrm{~g} / \mathrm{L}$ of glucose in $24 \mathrm{~h}$ (Table 1$)$. Since glucose concentration did not increase after further $24 \mathrm{~h}$, this time was considered optimal for hydrolysis. Therefore, these conditions $(2.25 \mu \mathrm{L} / \mathrm{mL}, 24 \mathrm{~h})$ were selected for the following experiments. Interestingly, glucose and xylose were the only sugars released by the action of the enzymes. In fact, fructose and sucrose concentrations remained constant over the time at all the tested enzyme concentrations (fructose $5 \mathrm{~g} / \mathrm{L}$, sucrose $29 \mathrm{~g} / \mathrm{L}$ ). On the other hand, the addition of amylase did not result in an increase of glucose concentration, indicating that pumpkin biomass used in this study did not contain amylose, differently from that reported by Chouaibi and co-workers (Chouaibi et al., 2020). This can be due to differences in quality and provenience of the feedstock, that can greatly affect its final sugar composition. These factors can influence in fact the physical properties of the feedstock like density, moisture content, micro-morphology, and rheological aspects. Furthermore, chemical characteristics of the feedstock are also influenced, such as chemical composition, molecular functional groups percentage, and inorganic species presence (Kim et al., 2012; Yan et al., 2020). Sucrose was the principal sugar in our pumpkin waste, that was characterized by the presence of a tiny peel fraction. Sucrose is mostly present in the pulp, thus it can be found at different levels in the wastes, depending on the type of peeling operation adopted in processing. After centrifugation of the enzymatic hydrolysate, the liquid part obtained was characterized for its composition besides sugars (Table 2). In particular, quantification of acetic acid was done because it is known to be an inhibitor of cell growth. This compound was present at the same concentration detected in the non-treated sample. Probably, acetic acid was generated during the prior biomass storage by microorganisms already present in the pumpkin waste. Nitrogen $(\mathrm{N})$ is an essential element for biomass production; nevertheless, lipid production is triggered by high $\mathrm{C} / \mathrm{N}$ ratio. When the $\mathrm{C} / \mathrm{N}$ ratio is low the cells invest nitrogen and carbon to produce biomass, whereas when the ratio is high the carbon is mainly directed to lipid production. In the pumpkin peels hydrolysate inorganic nitrogen $\left(\mathrm{NH}_{4}{ }^{+}\right)$was found only in traces. Total nitrogen, quantified using the Kjeldahl method, revealed that it contains mainly organic $\mathrm{N}$, that accounted for $2.4 \mathrm{~g} / \mathrm{L}$. Table 2 reports the final concentrations of the assayed components of the pumpkin peels hydrolysate after $24 \mathrm{~h}$ of enzymatic digestion.

\section{Analysis of growth and sugars utilization}

The availability of a pumpkin peels hydrolysate containing a sugars mixture mainly consisting of sucrose, glucose and fructose lead us to evaluate first the capacity of $R$. azoricus and $C$. oleaginosum to grow in presence of all these sugars. Cultures were performed on mineral medium (YNB), in order to avoid the utilization of other carbon sources, that could mask their ability to consume the provided sugars. In this way, we could also obtain quantitative data, in terms of sugar consumption rates and biomass yield. The importance to obtain information about growth and carbon source utilization is particularly strong due to the considerable metabolic diversity among oleaginous yeasts. These parameters are in fact known as key factors for selecting suitable species and for developing efficient fermentation processes.

The cultivation of $R$. azoricus on mineral medium containing a mixture of sucrose, glucose and fructose showed that this yeast started to consume sucrose even in presence of the other two sugars (Fig. 1A). However, a limited capacity to utilize glucose was observed. Glucose in fact was slowly and partially assimilated during the growth, in contrast to fructose that was completely utilized within $48 \mathrm{~h}$ (Fig. 1A). As a consequence, a low amount of yeast biomass was reached after $94 \mathrm{~h}$, corresponding to $4.3 \mathrm{~g} / \mathrm{L}$ of dry weight. Based on these results, we decided to analyze the growth in presence of either glucose or fructose as sole carbon sources. On glucose (Fig. 1B), R. azoricus started to grow exponentially, but again we observed that this sugar was partially consumed and, also in this case, a low amount of dry weight was obtained. Cellular viability was then tested and, surprisingly, we found that $40 \%$ of cells were not viable after $72 \mathrm{~h}$. These results in conclusion confirmed the impaired glucose assimilation observed in cultivation on the sugars mixture. By contrast, the cultivation on sole fructose revealed that this sugar does not cause the same early arrest of biomass production (Fig. 1C), allowing in fact to reach higher dry weight ( $9 \mathrm{~g} / \mathrm{L}$ ). By comparing the growth parameters (Table 3), we can see that the growth rate on glucose and on fructose containing media is rather similar, despite glucose consumption rate is higher than fructose. The main differences are found in terms of final amount of produced biomass and in biomass yield, indicating that fructose is metabolized in a more efficient way than glucose. These results were unexpected, because the growth of $R$. azoricus had been previously documented as occurring very efficiently on glucose-based media, especially for lipids production (Galafassi et al., 2012; Capusoni et al., 2017; Donzella et al., 2019). However, the media used for lipids production, containing yeast extract or corn steep, are not exclusively mineral as the one used in the present study. This prompted us to investigate if the addition of yeast extract to the medium containing the sugar mixture could help the cells, especially in glucose utilization. After $72 \mathrm{~h}$ (Fig. 1D), sucrose was completely hydrolyzed and glucose and fructose were depleted, leading to the production of $14 \mathrm{~g} / \mathrm{L}$ of 
biomass. These results demonstrate that enrichment of the medium by other nutrients, present in yeast extract, is essential for glucose metabolism and also improves sucrose consumption by this yeast species.

When $C$. oleaginosum was cultivated on mineral medium containing the same mixture of sugars (glucose, fructose and sucrose) we observed a very different behavior. The cells initially grew by using available glucose and fructose, that were depleted after $30 \mathrm{~h}$ (Fig. 2A). Sucrose was then hydrolyzed, indicating that the presence of monosaccharides delayed sucrose utilization. In this culture, the dry weight continued to increase until $120 \mathrm{~h}$, and in fact a higher amount of biomass was obtained ( $12 \mathrm{~g} / \mathrm{L}$ ), in comparison to $R$. azoricus (Table 3 ). The same behavior was observed by cultivating the cells on medium containing only glucose as carbon source (Fig. 2B): also in this case the biomass continued to increase in parallel with glucose utilization. By comparing the results obtained in terms of final biomass concentration and yield (Table 3), we can conclude that on mineral media $C$. oleaginosum is able to use glucose in a much more efficient way than $R$. azoricus. However, in this case, the addition of yeast extract to the medium containing the mixture did not improve sucrose utilization (Fig. 2C), demonstrating that enrichment of the medium by other nutrients does not contribute to improve sucrose metabolism.

The limited ability to metabolize glucose by $R$. azoricus and its early cellular death could lead to think to a phenomenon of glucose toxicity. In mammalian cells under hyperglycemic conditions, activation of the aldose reductase pathway causes redox unbalance and induction of oxidative stress, upregulating glucose toxicity pathways, as non-enzymatic glycation and disruption of mitochondrial respiratory chain (Tang et al. 2012). Aldose reductases are present in yeasts and have been studied mainly for the production of sugar alcohols (Park et al., 2016; Jagtap et al., 2019), but their role in regulation of sugar metabolism has been scarcely investigated.

However, it is noteworthy that this metabolic inability occurs only when $R$. azoricus grow on mineral media, and is removed by the addition of yeast extract, which is a rich source of nutrients. This reinforce the necessity of studies that carefully analyze growth parameters in order to identify the basis of metabolic diversity among oleaginous yeasts, as recently reported (Brandenburg et al., 2021 Chmielarz et al., 2021). This kind of information is often lacking because mineral media are not suitable for industrial bioprocesses.

\section{Lipids production from pumpkin peels waste-based medium}

With the aim of developing fermentative processes for the production of lipids from pumpkin wastes, shaken flask cultures of $R$. azoricus and $C$. oleaginosum were set up using pumpkin peels hydrolysate-based medium.

Cultivation of yeasts was carried out on medium (pH 5.5) containing nutrients exclusively derived from pumpkin peels hydrolysate (Table 2 ). After $42 \mathrm{~h}$ of $R$. azoricus cultivation, we observed that all the sugars were completely consumed, by producing $27.4 \mathrm{~g} / \mathrm{L}$ of dry weight (Fig. $3 \mathrm{~A}$ ). Acetic acid was also metabolized, as we previously reported by this species (Galafassi et al., 2012). Biomass dry weight further increased, reaching the concentration of $28.1 \mathrm{~g} / \mathrm{L}$ after $64 \mathrm{~h}$, probably due to the use of other undetected carbon sources present in the pumpkin peels hydrolysate (likely free amino-acids). This yeast biomass contained $39 \%$ of lipids, that corresponds to a concentration of $11 \mathrm{~g} / \mathrm{L}$, with a lipid yield of 0.22 (calculated on the consumed sugar).

When $C$. oleaginosum was cultivated on the same medium, glucose and fructose were exhausted after 65 h, but sucrose was only partially hydrolyzed (Fig. 3B). This indicates a slower utilization of this sugar, in comparison to $R$. azoricus, and in agreement with the results showed in Fig. $2 \mathrm{C}$. In addition, a lower level of lipids was obtained, representing $29 \%$ of yeast dry weight, that corresponds to a concentration of $7 \mathrm{~g} / \mathrm{L}$ after $94 \mathrm{~h}$. However, lipid yield was similar to that of $R$. azoricus.

In conclusion, these results indicate that the pumpkin peels waste represents a complete source of nutrients for yeast cultivation, allowing to obtain high concentrations of biomass. In addition, this medium also sustains lipid production ( $11 \mathrm{~g} / \mathrm{L}$ by $R$. azoricus and $7 \mathrm{~g} / \mathrm{L}$ by $C$. oleaginosum).

\section{Two-stage process in bioreactor for lipids production}

Based on these results, we decided to develop a fermentative process for lipids production by using the yeast $R$. azoricus, that exhibited the best performance on pumpkin wastes-based medium. Usually, the process for lipid production is performed in two stages, the first carried out at low $\mathrm{C} / \mathrm{N}$ ratio to produce high amount of cell biomass, and the second by feeding nutrients at high C/N ratio to trigger lipid accumulation (Ageitos et al., 2011).

The cultivation in bioreactor, under controlled conditions of oxygen and $\mathrm{pH}$, resulted in the production of $30 \mathrm{~g} / \mathrm{L}$ of biomass, already containing $37 \%$ of lipids, after $46 \mathrm{~h}$ of cultivation (Fig. 4). At this point, sucrose and glucose were depleted, whereas fructose was still present. In order to increase lipid content, we decided to feed the culture by using another industrial food waste coming from the production of candied fruits (a syrup from mango processing). This waste contains in fact high concentration of glucose and fructose, but does not contain nitrogen, making it a perfect $\mathrm{C}$ source for our purpose to unbalance the $\mathrm{C} / \mathrm{N}$ ratio of the medium. After further $44 \mathrm{~h}$ of process, all glucose and part of fructose were metabolized by the yeast (Fig. 4). Sugars were converted into lipids, allowing the yeast biomass to reach a lipid content of $55 \%$ of dry weight. The lipid concentration after $90 \mathrm{~h}$ of process was $24 \mathrm{~g} / \mathrm{L}$ (Fig. 4 ), that corresponded to a lipid productivity of $0.26 \mathrm{~g} / \mathrm{L} / \mathrm{h}$. Based on the sugars utilized the lipid yield was 0.29 .

These results represent a very promising starting point for developing a lipid production process. Similar results were reported by Slininger and co-workers (2016), that developed a very efficient two-stage process on undetoxified lignocellulose hydrolysate, by identifying top-performing lipids producing yeasts, and also close to the highest reported by Cho and Park (2018) from other organic wastes. Moreover, by enriching the initial medium with nitrogen we can increase the biomass production during the first step, reaching higher dry weight, that in the second step can account for higher final lipid concentration. Previously, by the same oleaginous species we reported a two stage process on glucose-based medium, performed by feeding nitrogen in the first step and glucose in the second step, that resulted in the production of $80 \mathrm{~g} / \mathrm{L}$ of yeast biomass containing $41 \%$ of lipid, and corresponding to a final lipid concentration of $33 \mathrm{~g} / \mathrm{L}$ (Capusoni et al., 2017). 
In conclusion, by the exclusive use of food wastes (pumpkin peels and candied fruits syrup), $R$. azoricus was able to efficiently grow and produce lipids with high productivity and yield.

\section{Conclusions}

This proof-of-concept study has shown the feasibility to produce yeast biomass and lipids in an economical way using a medium based on pumpkin wastes, demonstrating a possible process of upgrading low value industrial food wastes to high value products. The use of two inexpensive residues, i.e. pumpkin peels and syrup from candied fruits processing, for sustaining microbial oil production has been never reported before. They can therefore represent a renewable and low-cost feedstock to fulfil nutrients requirement of yeasts. Lipids can be extracted and used to produce biofuels and chemicals. Yeast biomass can in turn be used as a high-quality animal feed ingredient, because it is considered a well-balanced source of protein, and can provide also vitamins (mainly the B group) (Øverland et al., 2013). In conclusion, one of the main goals of circular economy, which is the reduction of wastes by recycle, could be addressed.

\section{Methods}

\section{Strains, media and growth conditions}

The yeast strains used in this work are wild type strain DBVPG 4620 reclassified as Rhodosporidiobolus azoricus (Capusoni et al., 2017) and wild type strain ATCC 20509 classified as Cutaneotrichosporon oleaginosum (Gujjari et al., 2011). For long-term storage, yeast strains were maintained at $-80{ }^{\circ} \mathrm{C}$ on $15 \%$ (v/v) glycerol.

YPD medium contained $10 \mathrm{~g} / \mathrm{L}$ yeast extract (Biolife, Italy) $20 \mathrm{~g} / \mathrm{L}$ peptone (Biolife, Italy) and $20 \mathrm{~g} / \mathrm{L}$ glucose (Sigma Aldrich, Italy).

YNB medium contained Yeast Nitrogen Base $0.17 \mathrm{~g} / \mathrm{L}$, (Difco BD, Italy), and $0.1 \mathrm{M}$ MES hydrate (Sigma Aldrich, Italy) to maintain pH 6. Sugars (sucrose, glucose, fructose from Sigma Aldrich, Italy) were added individually at $50 \mathrm{~g} / \mathrm{L}$, or in mixture to simulate the pumpkin peels hydrolysate composition.

Yeast cells were cultivated at $28^{\circ} \mathrm{C}$ in a rotary shaker at $150 \mathrm{rpm}$ in bluffed flasks with an air-liquid ratio of 1:5. Cells from pre-cultures (inoculated from glycerol stocks) grown overnight on YPD were harvested by centrifugation (5000 rpm/2300 rcf, 10 min in Eppendrof 5415D centrifuge) and inoculated at $\mathrm{OD}_{660} 0.1$ in YNB medium or at $\mathrm{OD}_{660} 0.4$ in pumpkin peels hydrolysate-based medium. Cell growth was monitored by measuring the increase of optical density at $660 \mathrm{~nm}\left(\mathrm{OD}_{660}\right)$ using a spectrophotometer (Eppendorf, Italy).

\section{Preparation of pumpkin peels hydrolysate}

Fresh pumpkin peels (from Azienda Agricola Paratorosso, Settala, Milano) were oven-dried over-night at $70^{\circ} \mathrm{C}$ and milled with a laboratory grinder Bimby TM 3300 to obtain a fine powder. The powder was stored at $4^{\circ} \mathrm{C}$ in a tightly closed jar.

Small scale enzymatic hydrolysis was carried by suspending the peel powder (solid loading of $12 \%(\mathrm{w} / \mathrm{v})$, in distilled water. The mixture was then sterilized in autoclave (Cavallo S.r.l., Milan, Italy) at $0.5 \mathrm{~atm}, 112^{\circ} \mathrm{C}$ for $30 \mathrm{~min}$. After cooling to $50^{\circ} \mathrm{C}$, the mixture was adjusted at pH 5.5 added with different amounts $\left(1.12,2.25,5.5,11.25,22.5 \mu \mathrm{L} / \mathrm{mL}\right.$ ) of Cellic CTec2 enzyme cocktail (Novozymes, Denmark) (hydrolytic activity $>1150 \mathrm{U} / \mathrm{mL}$ ) and incubated at $50{ }^{\circ} \mathrm{C}$ in an oil bath under magnetic stirring.

At different times, $0.5 \mathrm{~mL}$ aliquots were collected, and sugar content was analyzed by enzymatic assay. The higher scale hydrolysis was carried out in a 2-L bioreactor (Applikon Biotechnology, The Netherlands). The bioreactor filled with the reaction mixture $(650 \mathrm{~mL})$ was autoclaved for 1 hour at 1 atm, $121^{\circ} \mathrm{C}$. Temperature was set at $48{ }^{\circ} \mathrm{C}$, agitation at $650 \mathrm{rpm}$ and $\mathrm{pH}$ at 5.5. To control bacterial contamination, antibiotics were added (Ampicillin $100 \mu \mathrm{g} / \mathrm{mL}$, Kanamycin $10 \mu \mathrm{g} / \mathrm{mL}$ and Chloramphenicol $5 \mu \mathrm{g} / \mathrm{mL}$ ). The hydrolysis was started by the addition of enzymes (1.46 mL of Cellic CTec2). After $24 \mathrm{~h}$, the hydrolysate was centrifuged in sterile tubes at $5000 \mathrm{rpm} / 3214 \mathrm{rcf}$ in Eppendrof $5804 \mathrm{R}$ centrifuge for $1 \mathrm{~h}$, and the liquid phase stored at $-20^{\circ} \mathrm{C}$.

\section{Sugars and acetic acid determination}

The concentrations of sugars and acetic acid were determined by employing commercial enzymatic kits (K-GLUHK, K-SUFRG, K-XYLOSE by Megazyme Ltd, Ireland and 10148261035 by R-Biopharm AG, Germany, respectively). All the assays were performed in triplicate and standard deviations varied between 1 and $5 \%$. The biomass and product yields were calculated as the ratio between the total amount of biomass or products and the total amount of consumed sugars.

\section{Nitrogen determination}

Inorganic nitrogen was determined by employing a commercial enzymatic kit (10542946035 by R-Biopharm AG, Germany).

Total nitrogen concentration in culture supernatants was determined by Kjeldahl method using a SpeedDigester K-376 and a KjelMaster K-375 (Buchi Italia).

\section{Dry weight determination}

Cells were collected from the medium ( $1 \mathrm{~mL}$ or $2 \mathrm{~mL}$ of cell culture) by centrifugation ( $5 \mathrm{~min}$ at $13200 \mathrm{rpm} / 16100$ rcf in Eppendrof $5415 \mathrm{D}$ centrifuge). The pellets were dried overnight at $105^{\circ} \mathrm{C}$. In the case of pumpkin peels hydrolysate, the dry weight of the pellet present at $T_{0}$ was determined and subtracted to the value of the following measurements.

Lipid determination

Page 5/11 
Lipid content was determined via the sulfo-phospho-vanilline colorimetric method (Spinreact, Spain) on the washed cell pellets corresponding to approximately $30 \mathrm{OD}$, suspended in $0.5 \mathrm{~mL}$ of cold redistilled water. The assays were performed in triplicate and standard deviations varied between 1 and $5 \%$.

\section{Fed batch cultivation}

Fed-batch cultures were performed in a 2-L bioreactor (Applikon Biotechnology, The Netherlands), with a starting volume of $600 \mathrm{~mL}$. Pumpkin peel hydrolysate was used as medium for yeast cultivation. Temperature was set at $30^{\circ} \mathrm{C}$, the air inlet at $1 \mathrm{vvm}$ and the agitation at $500 \mathrm{rpm}$.

Dissolved oxygen concentration was measured by AppliSens oxygen probe (Applikon Biotechnology, The Netherlands), starting from $100 \%$ of saturation. Foam formation was controlled by the addition of a silicon antifoaming agent (Sigma 204). The pH, measured by AppliSens pH electrode (Applikon

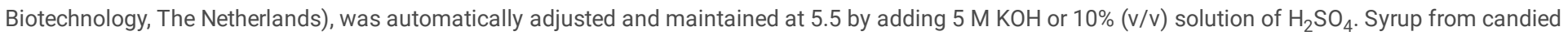
fruits (mango) manufacture (SVZ, Industrial Fruit \& Vegetable Ingredients, Breda, the Netherlands), diluted to glucose $199 \mathrm{~g} / \mathrm{L}$ and fructose $296 \mathrm{~g} / \mathrm{L}$, was supplied after $46 \mathrm{~h}$ in order to unbalance the $\mathrm{C} / \mathrm{N}$ ratio.

\section{Declarations}

\section{Acknowledgements}

The authors are grateful to Azienda agricola Pratorosso (Settala, Milano) for providing pumpkin peels. The sugar syrup was kindly supplied by SVZ (Industrial Fruit \& Vegetable Ingredients, Breda, the Netherlands).

\section{Funding}

This research did not receive any specific grant from funding agencies in the public, commercial, or not-for-profit sectors.

\section{Author contributions}

S. D. and I. S. contributed at the same extent to the study, for conceptualization, data curation, analysis and writing the draft. A. F.: investigation, analysis; L.P: contribution to discussion of the results; C. C.: conceptualization, supervision of investigation, writing the manuscript.

\section{Availability of data and materials}

The datasets used and/or analysed during the current study are available from

the corresponding author on reasonable request.

\section{Ethics approval and consent to participate}

Not applicable.

\section{Competing interests}

The authors declare that they have no competing interests

\section{References}

1. Ageitos, J.M., Vallejo, J.A., Veiga-Crespo, P., Villa, T.G., 2011. Oily yeasts as oleaginous cell factories. Appl. Microbiol. Biotechnol. 90, $1219-1227$. https://doi.org/10.1007/s00253-011-3200-z

2. Ahmad, F.B., Zhang, Z., Doherty, W.O.S., O'Hara, I.M., 2019. The prospect of microbial oil production and applications from oil palm biomass. Biochem. Eng. 143, 9-23. J. https://doi.org/10.1016/j.bej.2018.12.003

3. Béligon, V., Christophe, G., Fontanille, P., Larroche, C., 2016. Microbial lipids as potential source to food supplements. Curr. Opin. Food Sci. 7, 35-42. https://doi.org/10.1016/j.cofs.2015.10.002

4. Beopoulos, A., Nicaud, J.M., Gaillardin, C., 2011. An overview of lipid metabolism in yeasts and its impact on biotechnological processes. Appl. Microbiol. Biotechnol. 90, 1193-1206. https://doi.org/10.1007/s00253-011-3212-8

5. Blomqvist, J., Pickova, J., Tilami, S.K., Sampels, S., Mikkelsen, N., Brandenburg, J., Sandgren, M., Passoth, V., 2018. Oleaginous yeast as a component in fish feed. Sci. Rep. 8, 15945. https://doi.org/10.1038/s41598-018-34232-x

6. Brandenburg, J., Blomqvist, J., Shapaval, V. et al. Oleaginous yeasts respond differently to carbon sources present in lignocellulose hydrolysate. Biotechnol Biofuels 14, 124 (2021). https://doi.org/10.1186/s13068-021-01974-2

7. Capusoni, C., Rodighiero, V., Cucchetti, D., Galafassi, S., Bianchi, D., Franzosi, G., Compagno, C., 2017. Characterization of lipid accumulation and lipidome analysis in the oleaginous yeasts Rhodosporidium azoricum and Trichosporon oleaginosus. Bioresour. Technol. 238, 281289.https://doi.org/10.1016/j.biortech.2017.03.188

8. Carota, E., Crognale, S., D’Annibale, A., Gallo, A.M., Stazi, S.R., Petruccioli, M., 2017. A sustainable use of Ricotta Cheese Whey for microbial biodiesel production. Sci. Total Environ. 584-585, 554-560. https://doi.org/10.1016/j.scitotenv.2017.01.068 
9. Chatterjee, S., Mohan, S.V., 2018. Microbial lipid production by Cryptococcus curvatus from vegetable waste hydrolysate. Bioresour. Technol. 254, 284289. https://doi.org/10.1016/j.biortech.2018.01.079

10. Chattopadhyay, A., Mitra, M., Maiti, M. K., 2021. Recent advances in lipid metabolic engineering of oleaginous yeasts. Biotechnology Advances, 107722,ISSN 0734-9750, https://doi.org/10.1016/j.biotechadv.2021.107722

11. Chmielarz, M., Blomqvist, J., Sampels, S. et al. Microbial lipid production from crude glycerol and hemicellulosic hydrolysate with oleaginous yeasts. Biotechnol Biofuels 14, 65 (2021). https://doi.org/10.1186/s13068-021-01916-y

12. Cho H.U., Park J.M., 2018. Biodiesel production by various oleaginous microorganisms from organic wastes. Bioresour. Technol. $256,502-508$. https://doi.org/10.1016/j.biortech.2018.02.010

13. Chouaibi, M., Daoued, K. Ben, Riguane, K., Rouissi, T., Ferrari, G., 2020. Production of bioethanol from pumpkin peel wastes: Comparison between response surface methodology (RSM) and artificial neural networks (ANN). Ind. Crops Prod. 155, 112822. https://doi.org/10.1016/j.indcrop.2020.112822

14. Donzella, S., Cucchetti, D., Capusoni, C., Rizzi, A., Galafassi, S., Chiara, G., Compagno, C., 2019. Engineering cytoplasmic acetyl-CoA synthesis decouples lipid production from nitrogen starvation in the oleaginous yeast Rhodosporidium azoricum. Microb. Cell Fact. 18, 1-10. https://doi.org/10.1186/s12934019-1250-6

15. Dyer, J.M., Stymne, S., Green, A.G., Carlsson, A.S., 2008. High-value oils from plants. Plant J. 54, 640-655. https://doi.org/10.1111/j.1365313X.2008.03430.X

16. Foley, J. P., Kermanshahi, A., Beach, E. S., Zimmerman, J. B., 2012. Derivation and synthesis of renewable surfactants, Chem. Soc. Rev., 41, 1499-1518. https://doi.org/10.1039/C1CS15217C

17. Galafassi, S., Cucchetti, D., Pizza, F., Franzosi, G., Bianchi, D., Compagno, C., 2012. Lipid production for second generation biodiesel by the oleaginous yeast Rhodotorula graminis. Bioresour. Technol. 111, 398-403. https://doi.org/10.1016/j.biortech.2012.02.004

18. Gujjari, P., Suh, S.O., Coumes, K., Zhou, J.J., 2011. Characterization of oleaginous yeasts revealed two novel species: Trichosporon cacaoliposimilis sp. nov. and Trichosporon oleaginosus sp. nov. Mycologia 103, 1110-1118.

19. Huang, C., Chen, Xue fang, Xiong, L., Chen, Xin de, Ma, L. long, Chen, Y., 2013. Single cell oil production from low-cost substrates: The possibility and potential of its industrialization. Biotechnol. Adv. 31(2), 129-139. https://doi.org/10.1016/j.biotechadv.2012.08.010

20. Jagtap, S.S., Bedekar, A.A., Liu, J.J., Jin, Y.S., Rao, C. V., 2019. Production of galactitol from galactose by the oleaginous yeast Rhodosporidium toruloides IF00880. Biotechnol. Biofuels, 12, 1-13. https://doi.org/10.1186/s13068-019-1586-5

21. Jönsson L.J., Martín C., 2016. Pretreatment of lignocellulose: Formation of inhibitory by-products and strategies for minimizing their effects, Bioresour. Technol. 199, 103-112. https://doi.org/10.1016/j.biortech.2015.10.009

22. Kim, M.Y., Kim, E.J., Kim, Y.N., Choi, C., Lee, B.H., 2012. Comparison of the chemical compositions and nutritive values of various pumpkin (Cucurbitaceae) species and parts. Nutr. Res. Pract. 6, 21-27. https://doi.org/10.4162/nrp.2012.6.1.21

23. Koutinas A, Chatzifragkou A, Kopsahelis N, Papanikolaou S, Kookos I (2014) Design and techno-economic evaluation of microbial oil production as a renewable resource for biodiesel and oleochemical production. Fuel 116, 566-577.

24. Liu, Z., Moradi, H., Shi, S., Darvishi, F. (2021). Yeasts as microbial cell factories for sustainable production of biofuels. Renewable and Sustainable Energy Reviews. 143, 110907. https://doi.org/10.1016/j.rser.2021.110907

25. Matsakas, L., Bonturi, N., Miranda, E.A., Rova, U., Christakopoulos, P., 2015. High concentrations of dried sorghum stalks as a biomass feedstock for single cell oil production by Rhodosporidium toruloides. Biotechnol. Biofuels, 8, 4-9. https://doi.org/10.1186/s13068-014-0190-y

26. Metzger, J.O., Bornscheuer, U., 2006. Lipids as renewable resources: Current state of chemical and biotechnological conversion and diversification. Appl. Microbiol. Biotechnol. 71, 12-22. https://doi.org/10.1007/s00253-006-0335-4

27. Øverland, M., Karlsson, A., Mydland, L. T., Romarheim, O. H., Skrede, A., 2013. Evaluation of Candida utilis, Kluyveromyces marxianus and Saccharomyces cerevisiae yeasts as protein sources in diets for Atlantic salmon (Salmon salar). Aquaculture 402-403, 1-7.

28. Park, Y.C., Oh, E.J., Jo, J.H., Jin, Y.S., Seo, J.H., 2016. Recent advances in biological production of sugar alcohols. Curr. Opin. Biotechnol. $37,105-113$. https://doi.org/10.1016/j.copbio.2015.11.006

29. Qiao, K., Wasylenko, T.M., Zhou, K., Xu, P., Stephanopoulos, G., 2017. Lipid production in Yarrowia lipolytica is maximized by engineering cytosolic redox metabolism. Nat. Biotechnol. 35, 173-177. https://doi.org/10.1038/nbt.3763

30. Qin, L., Liu, L., Zeng, A.P., Wei, D., 2017. From low-cost substrates to Single Cell Oils synthesized by oleaginous yeasts. Bioresour. Technol. 245, 15071519. https://doi.org/10.1016/j.biortech.2017.05.163

31. Slininger, P. J., Dien, B. S., Kurtzman, C. P., Moser, B. R., Bakota, E. L., Thompson, S. R., O'Bryan, P. J., Cotta, M. A., Balan, V., Jin, M., Sousa Lda, C., Dale, B. E., 2016. Comparative lipid production by oleaginous yeasts in hydrolyzates of lignocellulosic biomass and process strategy for high titers. Biotechnol Bioeng. 113(8):1676-90. https://doi.org/10.1002/bit.25928. Epub 2016 Feb 3. Erratum in: Biotechnol Bioeng. 2016 Oct;113(10):2305. PMID: 26724417

32. Tai, M., Stephanopoulos, G., 2012. Engineering the push and pull of lipid biosynthesis in oleaginous yeast Yarrowia lipolytica for biofuel production. Metabolic Engineering, 15, 1-9. https://doi.org/10.1016/j.ymben.2012.08.007

33. Tang, W.H., Martin, K.A., Hwa, J., 2012. Aldose reductase, oxidative stress, and diabetic mellitus. Front. Pharmacol. 3, 1-8. https://doi.org/10.3389/fphar.2012.00087

34. Tasselli, G., Filippucci, S., Borsella, E., Gelosia, M., Cavalaglio, G., Turchetti, B., Sannino, C., Onofri, A., Mastrolitti, S., De Bari, I., Cotana, F., Buzzini, P., 2018. Yeast lipids from cardoon stalks, stranded driftwood and olive tree pruning residues as possible extra sources of oils for producing biofuels and biochemicals. Biotechnol. Biofuels 11, 147. https://doi.org/10.1186/s13068-018-1142-8 
35. Vorapreeda, T., Thammarongtham, C., Cheevadhanarak, S., Laoteng, K., 2012.Alternative routes of acetyl-CoA synthesis identified by comparative genomicanalysis: involvement in the lipid production of oleaginous yeast and fungi. Microbiology 158, 217-228.

36. Yan, J., Oyedeji, O., Leal, J.H., Donohoe, B.S., Semelsberger, T.A., Li, C., Hoover, A.N., Webb, E., Bose, E.A., Zeng, Y., Williams, C.L., Schaller, K.D., Sun, N., Ray, A.E., Tanjore, D., 2020. Characterizing Variability in Lignocellulosic Biomass: A Review. ACS Sustain. Chem. Eng. 8(22), 8059-8085. https://doi.org/10.1021/acssuschemeng.9b06263

37. Zhang, Y., Nielsen, J., Liu, Z., 2021. Yeast based biorefineries for oleochemical production. Curr. Opin. Biotechnol. 6, 26-34. https://doi.org/10.1016/j.copbio.2020.11.009

\section{Tables}

Table 1. Glucose concentration obtained after $24 \mathrm{~h}$ and $48 \mathrm{~h}$ of enzymatic digestion performed on pumpkin peel in small scale (2 mL).

\begin{tabular}{lll} 
Cellic CTec2 $(\mu \mathrm{L} / \mathrm{mL})$ & $\mathbf{2 4 ~ h - G l u c o s e ~}(\mathrm{g} / \mathrm{L})$ & $\mathbf{4 8 ~ h - ~ G l u c o s e ~}(\mathrm{g} / \mathrm{L})$ \\
\hline- & $3.9 \pm 0.3$ & $4.1 \pm 0.5$ \\
\hline 1.12 & $17.2 \pm 0.4$ & $19.2 \pm 0.3$ \\
\hline 2.25 & $23.6 \pm 0.5$ & $23.8 \pm 0.6$ \\
\hline 5.5 & $22.3 \pm 0.5$ & $22.7 \pm 0.8$ \\
\hline 11.25 & $21.8 \pm 0.7$ & $20.8 \pm 0.6$ \\
\hline 22.5 & $21.1 \pm 0.6$ & $19.3 \pm 0.7$
\end{tabular}

Table 2. Concentration of the main components of pumpkin peel hydrolysate (after $24 \mathrm{~h}$ of enzymatic digestion, large scale). The grams of each compound released per gram of biomass are also indicated.

\begin{tabular}{lll} 
Medium component & $\begin{array}{l}\text { Concentration } \\
(\mathbf{g} / \mathbf{L})\end{array}$ & $\mathbf{g} / \mathbf{g}_{\text {biomass }}$ \\
\hline Glucose & $18 \pm 1.5$ & 0.15 \\
\hline Sucrose & $29 \pm 1.8$ & 0.24 \\
\hline Fructose & $5 \pm 0.6$ & 0.04 \\
\hline Xylose & $0.4 \pm 0.08$ & 0.003 \\
\hline Acetic acid & $0.9 \pm 0.2$ & 0.0075 \\
\hline Nitrogen & $2.4 \pm 0.3$ & 0.02
\end{tabular}

Table 3. Growth parameters of $R$. azoricus and $C$. oleaginosum cultivated in shaken flasks on YNB medium added with different sugars.

\begin{tabular}{|c|c|c|c|c|c|c|c|c|c|c|}
\hline \multicolumn{5}{|c|}{ R. azoricus } & \multicolumn{6}{|c|}{ C. oleaginosum } \\
\hline & $\begin{array}{l}\max \\
\left(\mathrm{h}^{-1}\right)\end{array}$ & $\begin{array}{l}\mathrm{q} \\
(\mathrm{mmol} \\
\mathrm{h})\end{array}$ & $\begin{array}{l}\text { Biomass } \\
\text { yield } \\
\left(g_{d w} / g_{\text {sug }}\right)\end{array}$ & $\begin{array}{l}\text { Biomass } \\
(\mathrm{g} / \mathrm{L})\end{array}$ & $\begin{array}{l}\text { Consumed } \\
\text { sugars } \\
(\mathrm{g} / \mathrm{L})\end{array}$ & $\begin{array}{l}\max \\
\left(\mathrm{h}^{-1}\right)\end{array}$ & $\begin{array}{l}\mathrm{q} \\
\left(\mathrm{mmol}_{\text {sug }} /\right. \\
\left.\mathrm{g}_{\mathrm{dw}} / \mathrm{h}\right)\end{array}$ & $\begin{array}{l}\text { Biomass } \\
\text { yield } \\
\left(g_{d w} / g_{\text {sug }}\right)\end{array}$ & $\begin{array}{l}\text { Biomass } \\
(\mathrm{g} / \mathrm{L})\end{array}$ & $\begin{array}{l}\text { Consumed } \\
\text { sugars } \\
(\mathrm{g} / \mathrm{L})\end{array}$ \\
\hline Glucose & $0.21 \pm 0.02$ & $3.40 \pm 0.09$ & $0.20 \pm 0.04$ & $4.10 \pm 0.24$ & $20 \pm 1.00$ & $0.22 \pm 0.09$ & $3.21 \pm 0.21$ & $0.33 \pm 0.09$ & $12.00 \pm 0.51$ & $36 \pm 1.3$ \\
\hline Fructose & $0.23 \pm 0.03$ & $2.51 \pm 0.17$ & $0.32 \pm 0.07$ & $9.01 \pm 0.21$ & $28 \pm 1.50$ & ND & ND & ND & ND & ND \\
\hline Glu+Fru+Suc & $0.22 \pm 0.02$ & ND & $0.26 \pm 0.09$ & $4.30 \pm 0.12$ & $34 \pm 1.22$ & $0.26 \pm 0.08$ & ND & $0.21 \pm 0.06$ & $12.06 \pm 0.46$ & $33 \pm 0.97$ \\
\hline
\end{tabular}

ND: not determined

\section{Figures}


A

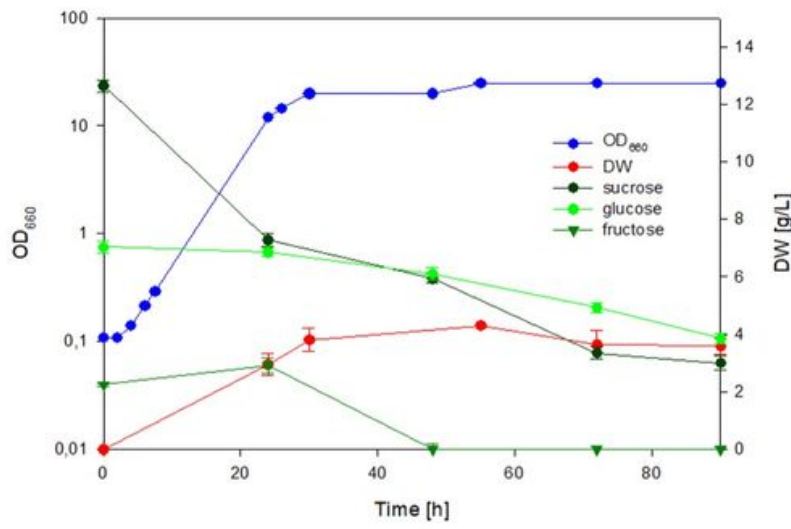

C

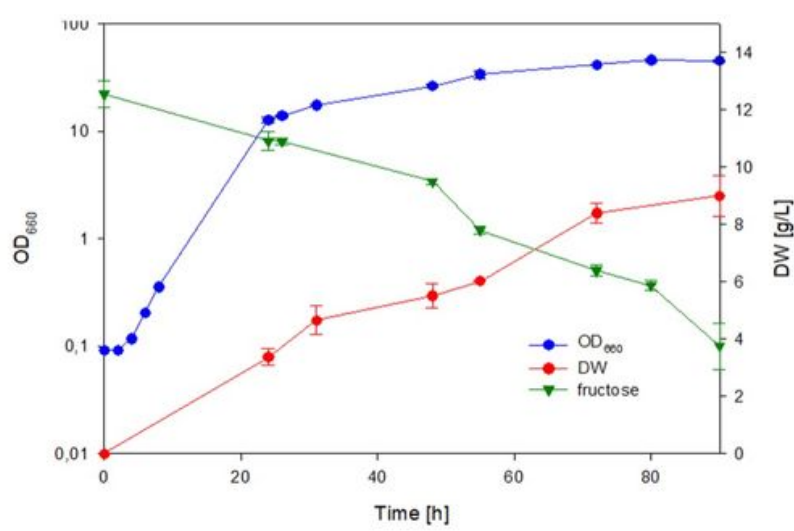

B

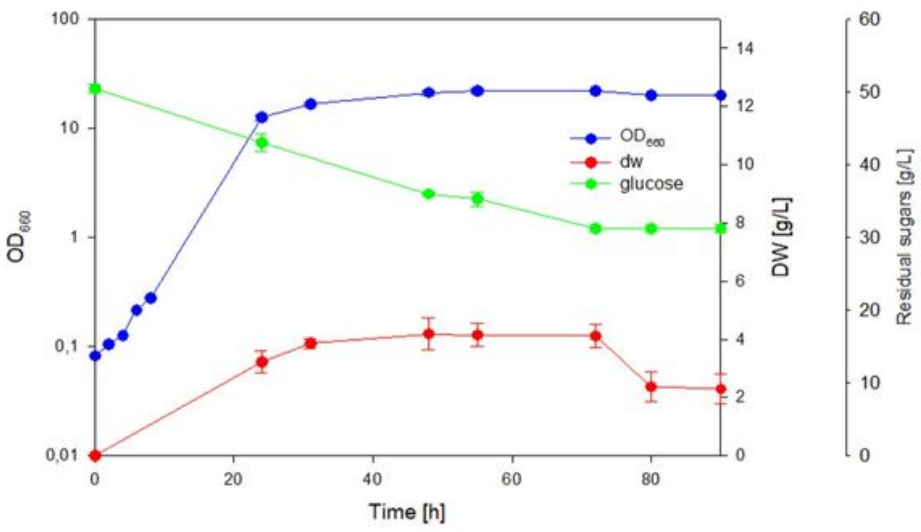

D

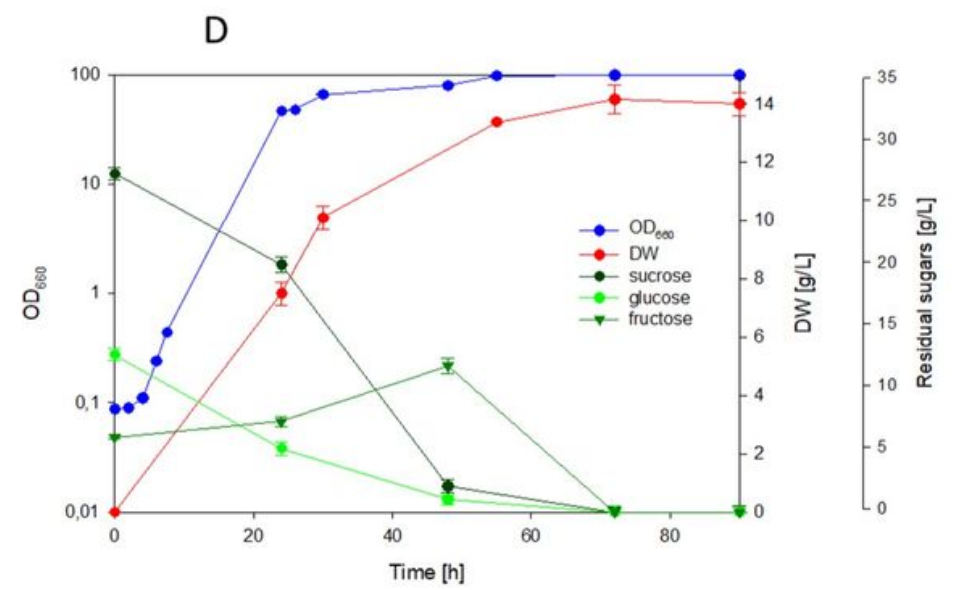

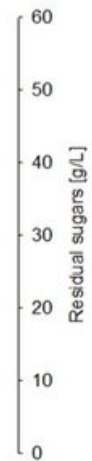

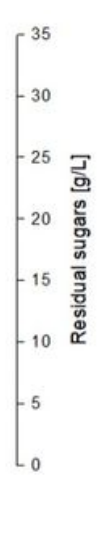

\section{Figure 1}

Cultivation of R. azoricus on YNB medium containing: $30 \mathrm{~g} / \mathrm{L}$ of sucrose, $15 \mathrm{~g} / \mathrm{L}$ of glucose and $5 \mathrm{~g} / \mathrm{L}$ of fructose (A); $50 \mathrm{~g} / \mathrm{L}$ of glucose (B); $50 \mathrm{~g} / \mathrm{L}$ of fructose (C); $30 \mathrm{~g} / \mathrm{L}$ of sucrose, $15 \mathrm{~g} / \mathrm{L}$ of glucose, $5 \mathrm{~g} / \mathrm{L}$ of fructose and $1 \mathrm{~g} / \mathrm{L}$ of yeast extract.

A

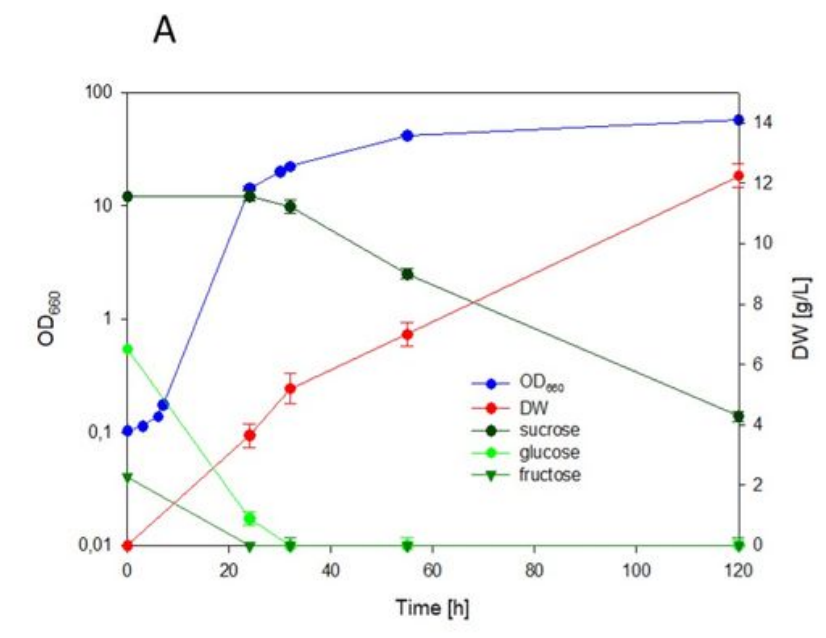

B

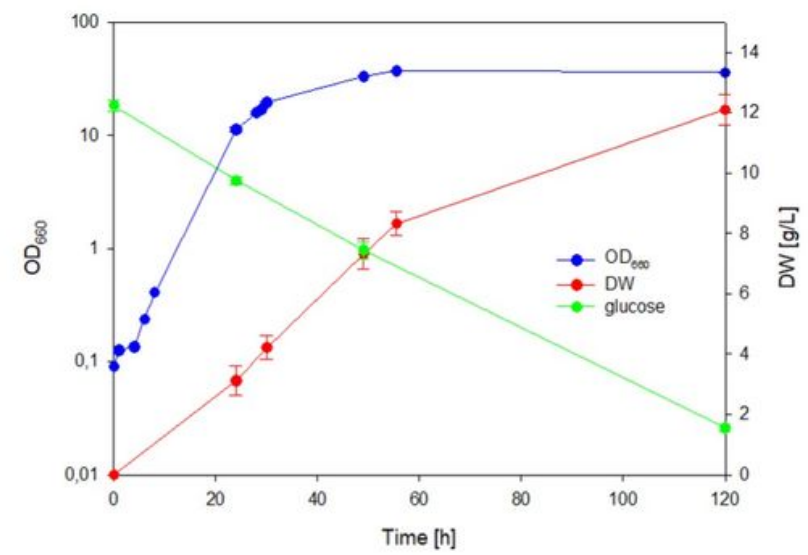

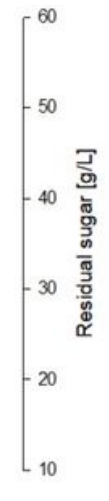

Figure 2

Cultivation of C. oleaginosum on YNB medium containing: $30 \mathrm{~g} / \mathrm{L}$ of sucrose, $15 \mathrm{~g} / \mathrm{L}$ of glucose and $5 \mathrm{~g} / \mathrm{L}$ of fructose (A); $50 \mathrm{~g} / \mathrm{L}$ of glucose (B). 
A

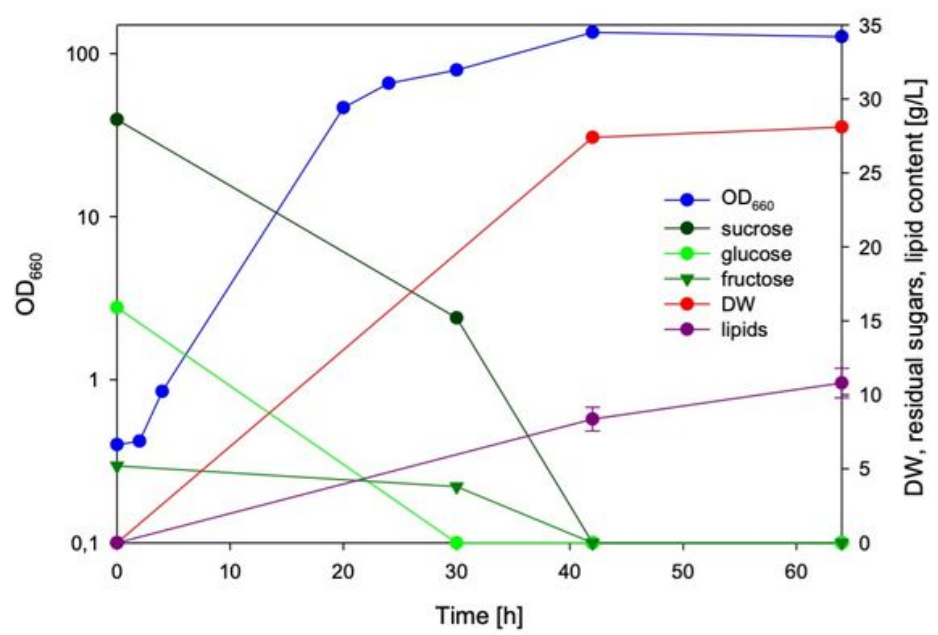

B

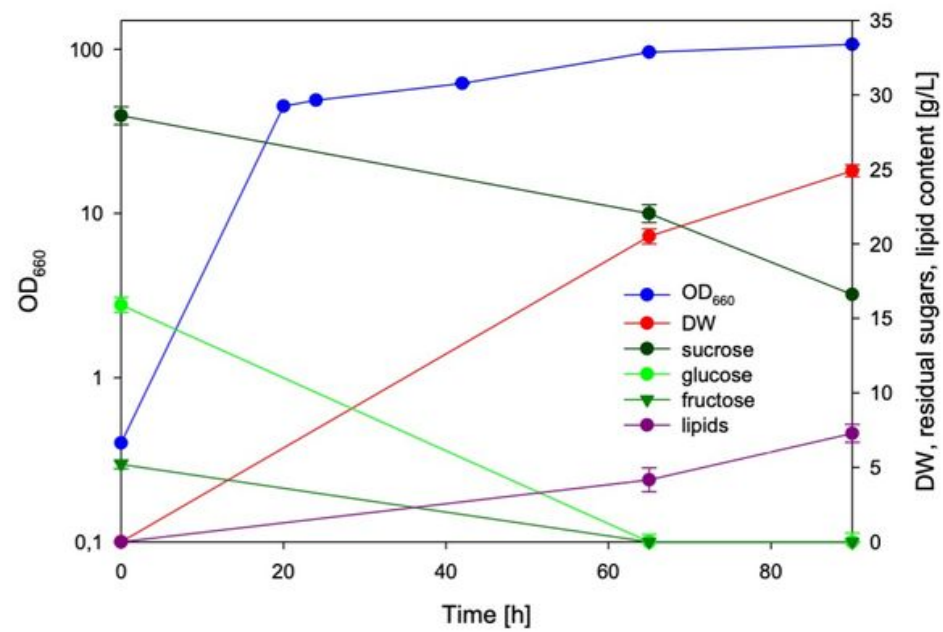

Figure 3

Cultivation of R. azoricus (A) and C. oleaginosum (B) in shaken flasks on pumpkin peel hydrolysate-based medium.

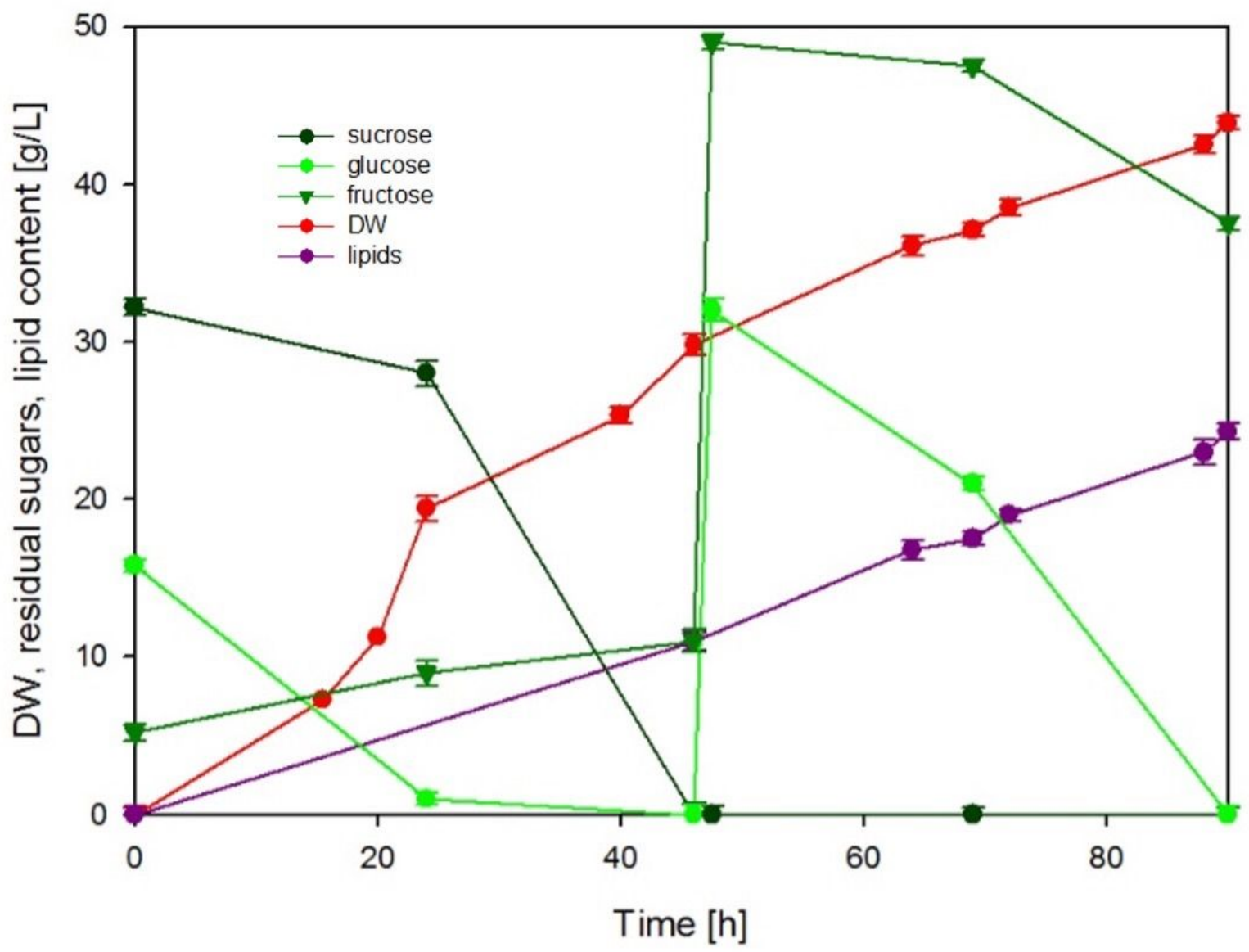


Figure 4

Cultivation of R. azoricus in 2-L bioreactor on pumpkin peel hydrolysate-based medium.

Page $11 / 11$ 